\title{
Tax-Competition with Involuntary Unemployment
}

\author{
Thomas Eichner \\ Thorsten Upmann
}

CESIFO WORKING PAPER NO. 3048

CATEgory 1: Public FinANCE

MAY 2010

\footnotetext{
An electronic version of the paper may be downloaded

- from the SSRN website: www.SSRN.com

- from the RePEc website: - from the CESifo website: 


\title{
Tax-Competition with Involuntary Unemployment
}

\begin{abstract}
In the present paper we extend the classical tax-competition framework of Zodrow and Mieszkowski (1986) by modelling involuntary unemployment and by allowing for labour taxation as a second source of public funds. For a large class of production functions (including CES), it turns out that tax competition is characterized by underprovision of public goods, and by positive taxes on both labour and capital. We thus conclude that the results of Zodrow and Mieszkowski survive some important and substantial modifications of the framework, and are thus more general than recently suggested elsewhere.
\end{abstract}

JEL-Code: H21, H71, H72, J51.

Keywords: tax competition, capital and labour taxation, involuntary unemployment, efficient bargains.

\author{
Thomas Eichner \\ Department of Economics \\ University of Hagen \\ Universitätsstrasse 41 \\ 58097 Hagen \\ Germany \\ Thomas.Eichner@FernUni-Hagen.de
}

\author{
Thorsten Upmann \\ University Duisburg-Essen \\ Mercator School of Management \\ Lotharstrasse 65 \\ 47057 Duisburg \\ Germany \\ Thorsten.Upmann@uni-duisburg-essen.de
}

February 12, 2010. 


\section{Introduction}

In the literature on tax competition, it is argued that capital taxation leads to inefficient low capital tax rates and thus to underprovision of public goods. Zodrow and Mieszkowski (1986) were the first who deduced this result very clearly for the case of a large number of regions with perfectly mobile capital. In this framework, a second factor of production, assumed to be fixed in supply and interpreted as land, earns residual profits as rent income. Subsequently the model of Zodrow and Mieszkowski has been extended in many directions to accommodate various real-world features. ${ }^{1}$

One particularly interesting extension is to augment the strategy space by allowing governments to compete over source-based capital taxes and residencebased labour taxes. This has first been done by Bucovetsky and Wilson (1991), who find zero capital tax rates and positive labour tax rates for small economies with perfectly competitive labour markets. The reason for their result is that since mobile capital is perfectly elastically supplied while immobile labour supply is of finite elasticity, the burden of a capital tax would ultimately be borne by labor anyway. It is thus more efficient to tax the latter directly.

Amazingly, only few authors have introduced (involuntary) unemployment into the Zodrow-Mieszkowski framework, although the presence of unemployment seems to be one of the main rationales for capital tax competition. For, the attraction of new capital, or the avoidance of capital flight, not only serves to broaden the tax base, and thus to collect public funds, but also, and frequently in the first instance, to create new jobs (or to prevent the loss of existing ones). But if employment effects represent a crucial motive for alluring capital, unemployment should seriously be considered in models of capital-tax competition.

One of the notable contributions where the presence of unemployment has been incorporated into the framework of interjurisdictional tax competition is the article of Fuest and Huber (1999). Applying a right-to-manage model where governments compete over capital and labour taxes, these authors show that tax competition brings about negative capital tax rates. More recently Ogawa et al. (2006) also introduced labour market imperfections into the original Zodrow-Mieszkowski setting by using a fixed-wage approach. They point out that the optimal capital

\footnotetext{
${ }^{1}$ The seminal work of Zodrow and Mieszkowski intentionally abstracts from many real world details such as consumption taxes, profit taxes or social insurance policies. Some of these aspects have been analyzed in the context of tax competition by, for example, Gabszewicz and van Ypersele (1996), Lejour and Verbon (1996), Richter and Schneider (2001) and Aronsson and Wehke (2008).
} 
tax rate is generically not zero, even if head taxes on immobile residents are available, and that tax competition may lead to overprovision of local public goods. However, these results are somewhat unsatisfactory when confronted with a realworld perspective: neither are actual capital taxes negative, as suggested by the model of Fuest and Huber, nor is labour left untaxed, as assumed by Ogawa et al. Rather, Eurostat (2008) reports that in the EU 27 in the year 2006 the average implicit tax rate on labour amounts to $34.8 \%$, while the average implicit tax rate on capital amounts to $29 \%$. In order to accommodate for both features, we extend the classical Zodrow-Mieszkowski framework.

Since the paper of Zodrow and Mieszkowski is one of the most influential contributions to tax competition, it is important to fully understand both its scope and its limitations. In this paper we target at this issue by applying an alternative, more sophisticated labour-market model, and by adding a labour tax as a second instrument to a government's strategy set. In this way, we are able to scrutinize the robustness of the results of the aforementioned literature and to elaborate the interaction between capital and labour taxes when countries (or regions) facing employment problems compete for mobile capital. Using an efficient bargaining model, where a labour union and an employers' association negotiate over wages and employment, ${ }^{2}$ we find for a large class of production functions, including among others CES functions, that (i) capital and labour tax competition results in an underprovision of public goods, and that (ii) capital and labour tax rates are both positive. ${ }^{3}$ Hence, disregarding "exotic" specifications of the production function (which require, among other things, capital and labour to be strong complements), neither subsidization of capital nor overprovision of public goods materializes in equilibrium. As a consequence, while our findings are thus at variance with those of Fuest and Huber (1999) and Ogawa et al. (2006), they demonstrate that the original results of Zodrow and Mieszkowski (1986) - underprovision of public goods and positive capital tax rates - continue to hold in the present setting, and are thus more general than suggested previously.

Another point is worthwhile to be emphasized. The fact that capital and labour demand as well as the wage rate are jointly, that is endogenously, determined, implies that both the capital and the labour tax exert distortionary effects

${ }^{2}$ In Europe nationally-based industrial unions (e.g. in Germany the IG Metall representing about 2.3 million workers in various industries) and representatives of the employers frequently bargain over wage rates, working time and employment simultaneously.

${ }^{3}$ The latter result is in line with the optimal capital taxation literature with unemployment, see e.g. Koskela and Schöb (2002) and the references cited therein. However, in Koskela and Schöb (2002) the public good provision is assumed to be constant and thus their model differs from the Zodrow and Mieszkowski framework. 
on production decisions. In order to balance these distortions, the government arguably taxes both factors at positive rates. This implies that the merit of the labour tax over the capital tax, which holds if labour is fixed in production, vanishes with the introduction of variable employment of labour and in particular with involuntary unemployment. More generally, labour taxation is no longer per se superior to capital taxation from the viewpoint of optimal taxation theory.

The rest of the paper is organized as follows. Section 2 sets up the model. In Section 3 we present the negotiations on the labour market and characterize the corresponding labour market equilibria. Comparative statics of the labour market are conducted in Section 4. Our results are contained in Section 5, where we investigate the equilibrium tax rates and the equilibrium provision level of public services. Finally, we summarize and conclude in Section 6 .

\section{The Model}

We model a federal state that is composed of $n$ identical jurisdictions, $n \geq 2$. The economy of each jurisdiction consists of households, firms and a government. We assume that households are identical in their tastes, but differ with respect to their income and leisure time. Each household's utility depends on the provision of a local public good, on private consumption and on leisure time. Preferences are assumed to be additively separable and linear in private consumption, so that we can write a household's utility as ${ }^{4}$

$$
U(X, P, T)=X+v(P)+u(T)
$$

where $X$ and $P$ denote the consumption levels of the private and the public good respectively, and $T$ denotes the amount of leisure time. The sub-utility function $u$ is assumed to be increasing, while $v$ is increasing and strictly concave.

We distinguish between three types of households: employed workers, unemployed workers and firm owners. The group of workers (or labourer households) consists of a total mass $N>0$; of these, households of mass $L \in[0, N]$ are employed, and of mass $N-L$ are unemployed. ${ }^{5}$ While $N$ is assumed to be exogenously given, the number of employed households is determined endogenously on the labour market (to be specified below). For institutional reasons, labourers can only obtain full employment contracts, so that they are either unemployed with maximal leisure time, say $\bar{T}$, or have a full-time job with $\bar{T}-1$ units of time left

\footnotetext{
${ }^{4}$ We omit any region-specific index throughout, for we deal with a representative region without the need to take into account the behaviour of any competing region explicitly.

${ }^{5}$ For ease of presentation we will speak of $N$ respectively $L$ labourer households in the following.
} 
for leisure. An employed household receives a real labour income equal to the real wage $w$ earned from a full-employment contract minus the burden of a proportional tax on labour income with tax rate $t$, i. e., $(1-t) w$. Thus, from his/her working activity each employed labourer receives private utility of $(1-t) w+u(\bar{T}-1)$; correspondingly, the utility level of an unemployed household is given by $\bar{u}:=u(\bar{T})$. For convenience, we normalize $u$ so that $u(\bar{T}-1)=0$. Then $\bar{w}:=\bar{u} /(1-t)$ is the reservation wage below which no household is willing to work. This implies that labour supply equals zero for all $w<\bar{w}$, equals $N$ for all $w>\bar{w}$, and is indeterminate, i. e., it is set-valued and equal to $[0, N]$ for $w=\bar{w}$.

Finally, the third group of households consists of $M$ identical fully employed firm-owners who all receive the same income. These households obtain part of their income in the form of untaxed dividends paid out of firms' aggregate profits $\Pi$. In addition, each household - labourer and firm owner - is endowed with $\bar{K} /(N+M)$ units of capital, which he/she inelastically supplies on the capital market, and for which he/she receives the net interest rate $\rho$ (per unit) of return. ${ }^{6}$ To summarize, the utility level of an employed worker is given by $(1-t) w+$ $\rho \bar{K} /(N+M)+v(P)$; of an unemployed worker, by $\rho \bar{K} /(N+M)+v(P)+\bar{u}$; and of a manager household by $\Pi / M+\rho \bar{K} /(N+M)+v(P)$.

The single consumption good is produced by a competitive industry consisting of identical firms. Each firm produces its output by means of three factors: labour, variable capital, and a fixed factor such as land or fixed capital. The production technology features constant returns to scale with respect to all three factors. For convenience, we suppress the fixed factor as an argument of the production function, and write output as $f(L, K)$, where $K$ and $L$ denote the employment levels of capital and labour, respectively. ${ }^{7}$

We assume that $f$ is twice continuously differentiable, with both factors possessing positive, $f_{K}, f_{L}>0$, but decreasing marginal products, $f_{K K}, f_{L L}<$ 0 . (Subindices of $f$ denote partial derivatives.) Also we assume that $A:=$ $f_{L L} f_{K K}-f_{L K}^{2}>0$. Moreover, let $f(0, K)=f(L, 0)=0, \forall K, L$, and assume that $f_{L}(L, \bar{K})>\bar{w}$ for $L \rightarrow 0$, and $f(N, \bar{K})<\bar{K} f_{K}(N, \bar{K})-N \bar{w}$. Normalizing the

\footnotetext{
${ }^{6}$ We may drop the additive separability between private consumption and leisure time if we were to assume that income consists of labour income exclusively. In this case capital income must accrue to either firm owners or a separate group of households, say capital owners.

${ }^{7}$ Since the industry consists of identical competitive firms employing a linearly homogeneous production function $\hat{f}(L, K, H)$, where $H$ denotes the level of all fixed factors of production, such as land and fixed capital, the aggregate production function coincides with firm-level production function. That is, $f$ may equally be interpreted as a firm's or as the industry's production function.
} 
price of the output good to unity, aggregate profits can then be written as

$$
\pi=\Pi(L, K, w, r):=f(L, K)-w L-r K
$$

where $r$ denotes the after-tax price of capital, which is composed of the (nationwide) net-return to capital $\rho$ plus a specific tax $\tau$ levied by the local government, i. e., $r \equiv \rho+\tau .^{8}$

Before firms decide about the amount of capital employed in production, the wage rate and the employment level are determined on the labour market. Thus, capital demand depends on the outcome of labour market negotiations and is implicitly defined by $f_{K}(L, K)=r$, yielding by means of the implicit function theorem, $K=\kappa(r, L)$, with

$$
\frac{\partial K}{\partial r}=\frac{\partial \kappa(r, L)}{\partial r}=\frac{1}{f_{K K}}<0 \quad \text { and } \quad \frac{\partial K}{\partial L}=\frac{\partial \kappa(r, L)}{\partial L}=-\frac{f_{L K}}{f_{K K}} .
$$

Capital demand declines with its after-tax price, and rises [declines] with the amount of labour used in production, if $f_{L K}>0[<0]$. For future reference, we denote by $\varepsilon_{r}^{\kappa}:=\frac{\partial \kappa}{\partial r} \frac{r}{K}=\frac{f_{K}}{K f_{K K}}$, and $\varepsilon_{L}^{\kappa}:=\frac{\partial \kappa}{\partial L} \frac{L}{K}=-\frac{f_{L K}}{f_{K K}} \frac{L}{K}$ the elasticity of capital demand with respect to $r$ and $L$, respectively.

The local government seeks to maximize the sum of its residents' utilities, that is

$$
(1-t) w L+(N-L) \bar{u}+(N+M) v(G)+\pi+\rho \bar{K} .
$$

The provision of the public good is financed by taxes on capital and labour, $\tau$ and $t$, respectively. We assume that the local government produces one unit of the public good by giving up one unit of the private good. Hence, we may view the provision of the local public good as public supply of private goods, or, alternatively, as being publicly produced by means of a one-to-one technology. Thus, the equation

$$
w L t+K \tau=G
$$

constitutes the public budget constraint of the (representative) jurisdiction.

\section{The Labour Market Model}

The labour market is characterized by negotiations between a labour union and an employers' association. The labour union, acting on behalf of the interest of

\footnotetext{
${ }^{8}$ While labour is inter-regionally immobile, variable capital is completely mobile across regions. The net-return $\rho$ is thus determined on the international capital market through equalizing demand and supply. However, since $\rho$ is viewed as a given constant from the perspective of a single region, there is no need to account for the functioning of the capital market explicitly.
} 
all workers, maximizes the sum of its members' utilities; or, in a framework of uncertainty, the representative members' expected utility:

$$
\Psi(w, L):=L u((1-t) w)+(N-L) \bar{u},
$$

where $L$ denotes the number of workers who obtain a job. On the other side, the interests of the firms are represented by an employers' federation seeking to maximize aggregate profits $\Pi(L, K, w, r)$.

We assume that both the wage rate and the employment level are determined by negotiations between the labour union and the employers' federation in an efficient way. That is, once an agreement is reached there is no room for renegotiations such that both parties can be made better off. Gerber and Upmann (2006) provide a couple of arguments in favour of efficient bargains. ${ }^{9}$ Although arguments may be found why negotiations may stop short of an efficient outcome, for example, imperfect information and uncertainty, we shall follow their arguments here and presume efficient bargains. ${ }^{10}$

As is well known we can characterize the outcome of any efficient bargaining solution as the intersection of two curves in the employment-wage space. Restricting our attention to the (asymmetric) Nash bargaining solution, the outcome of the negotiations between the employers' association and the labour union may be found as the point of intersection of the Nash curve with the Pareto curve. Both curves can be derived as the solution of the following maximization problem:

$$
\begin{aligned}
\max _{w, L} & {[\Psi(w, L)-N \bar{u}]^{\mu}[\Pi(L, K, w, r)]^{1-\mu} } \\
= & {[L((1-t) w-\bar{u})]^{\mu}[f(L, K)-r K-w L]^{1-\mu}, }
\end{aligned}
$$

where $\mu \in[0,1]$ and $1-\mu$ represent the bargaining power of the labour union and the employers' federation, respectively, and $N \bar{u}$ and 0 are the disagreement utilities of the labour union and the employers' association, respectively. The bargaining parties take into account that once they have agreed on some tuple $(w, L)$, firms subsequently choose $K=\kappa(r, L)$. Thus, $K$ is subsequently evaluated along the labour demand curve $\kappa$.

\footnotetext{
${ }^{9}$ These authors have also shown that in such a setting the negotiations between the firm/employers' association and a labour union constitute a bargaining problem in the sense of formal bargaining theory.

${ }^{10}$ Due to the similarity of the formal analysis of the efficient bargaining model with the rightto-manage approach, the monopolistic union, and the insider-dominated union, which has been demonstrated by Creedy and McDonald (1991), Bayındır-Upmann and Raith (2003, 2005) and Upmann (2009), we may expect that an analysis similar to the present one holds for alternative labour market models as well. We conjecture that the capital subsidy result of Fuest and Huber (1999) does not result from the right-to-manage-approach but from taxing profits by 100 percent.
} 
The first-order conditions of this maximization problem yield the Pareto curve and the Nash curve. The former is defined as the set of all employment-wage combinations such that both parties' indifference curves are tangent to each other,

$$
\sigma:=\frac{w(1-t)}{w(1-t)-\bar{u}}=\frac{w}{w-f_{L}(L, K)},
$$

while the latter determines the bargained wage as the weighted average of the marginal and average productivity of labour, net of the cost of other factors, ${ }^{11}$

$$
w=\mu \frac{f(L, K)-r K}{L}+(1-\mu) f_{L}(L, K),
$$

where $K=\kappa(r, L)$. Taken together, eqs (1) and (2) determine the negotiated wage rate and the negotiated employment level. Note that eq. (1) implies $\sigma>1$, while eq. (2) implies $w \geq f_{L}$.

\section{Comparative Statics of the Labour Market}

Before we turn to an equilibrium of our tax-competition game, we investigate the effects the tax rates $t$ and $\tau$ impose on the negotiated wage and the employment level. To this end, we implicitly differentiate eqs (1), (2), and rearrange terms to obtain

$$
\begin{aligned}
& \frac{\partial w}{\partial \tau}=\frac{1}{L}\left(\frac{w}{\sigma} \frac{f_{L K}}{A}-\mu K\right), \\
& \frac{\partial L}{\partial \tau}=-\frac{f_{L K}}{A} \\
& \frac{\partial w}{\partial t}=\frac{f_{L}}{1-t}\left(1-\mu-\frac{1}{\lambda \sigma}\right)>0, \\
& \frac{\partial L}{\partial t}=\frac{f_{L}}{1-t} \frac{f_{K K}}{A}<0,
\end{aligned}
$$

where $\lambda:=\left(A / f_{K K}\right)(L / w)<0$. Finally, substituting $L(\tau, t)$ into $\kappa$, and differentiating the result, $K=\tilde{\kappa}(\tau, t):=\kappa(\rho+\tau, L(\tau, t))$, yields

$$
\begin{aligned}
& \frac{\partial K}{\partial \tau}=\frac{\partial \tilde{\kappa}}{\partial \tau}=\frac{f_{L L}}{A}<0, \\
& \frac{\partial K}{\partial t}=\frac{\partial \tilde{\kappa}}{\partial t}=-\frac{f_{L}}{1-t} \frac{f_{L K}}{A} .
\end{aligned}
$$

When the government increases the labour tax, a higher wage rate is required to compensate workers for the induced fall in the after-tax wage rate. With a vertical Pareto curve (refer fn. 11), there is no scope for avoiding a corresponding decrease in employment. The effects of the capital tax rate on the outcome of the labour

\footnotetext{
${ }^{11}$ It is straightforward to verify that, due to the linearity of utility in income, the Pareto curve is vertical, while the Nash curve is decreasing in the $(L, w)$-space.
} 
market, however, depend on whether capital and labour are substitutes $\left(f_{L K}<0\right)$ or complements $\left(f_{L K}>0\right)$. In the first case, a reduction in the demand for capital is (partially) compensated by expanding the use of labour; this is achieved, though, at the expense of a reduced wage rate. If, however, capital and labour are complements, employment falls along with capital demand, while the effect on the wage rate is ambiguous.

\section{Tax Competition}

Having characterized the tax-induced effects on any equilibrium of the labour market, we are now in a position to elaborate the optimal tax policies of a government of a small jurisdiction - and thus the properties of the symmetric equilibrium of tax competition. In order to derive the optimal tax rates, we evaluate the governmental objective function along the equilibrium path of the labour market:

$$
\begin{aligned}
W(\tau, t):= & f(L(\tau, t), \tilde{\kappa}(\tau, t))-(t w(\tau, t) L(\tau, t)+\tau \tilde{\kappa}(\tau, t)) \\
& +(\bar{K}-\tilde{\kappa}(\tau, t)) \rho+(N-L(\tau, t)) \bar{u}+(N+M) v(G(\tau, t)) .
\end{aligned}
$$

Setting $\frac{\partial W}{\partial t}=0$, using our comparative static results and solving for the aggregate marginal utility of the public good, $V^{\prime}(G):=(N+M) v^{\prime}(G)$, we arrive at

$$
V^{\prime}(G)=\frac{\mathcal{Z}_{t}}{\mathcal{Z}_{t}+\mathcal{T}_{t}}=\frac{\left((1-\mu) t f_{L}+(1-t) w\right) A L}{\left((1-\mu) t f_{L}+(1-t) w\right) A L+f_{L}\left(t f_{L} f_{K K}-\tau f_{L K}\right)}
$$

where

$$
\begin{aligned}
\mathcal{Z}_{t} & :=t\left(w-f_{L}\right) \frac{\partial L}{\partial t}+t L \frac{\partial w}{\partial t}+w L=L\left(w+(1-\mu) f_{L} \frac{t}{1-t}\right), \\
\mathcal{T}_{t} & :=\left(\tau \frac{K}{L} \varepsilon_{L}^{K}+t f_{L}\right) \frac{\partial L}{\partial t}=\frac{f_{L}}{(1-t) A}\left(t f_{L} f_{K K}-\tau f_{L K}\right) .
\end{aligned}
$$

Similarly, setting $\frac{\partial W}{\partial \tau}=0$ and solving for the term $V^{\prime}(G)$ yields ${ }^{12}$

$$
V^{\prime}(G)=\frac{\mathcal{Z}_{\tau}}{\mathcal{Z}_{\tau}+\mathcal{T}_{\tau}}=\frac{(1-\mu t) A K}{(1-\mu t) A K+\tau f_{L L}-t f_{L} f_{L K}}
$$

where

$$
\begin{aligned}
\mathcal{Z}_{\tau} & :=t\left(w-f_{L}\right) \frac{\partial L}{\partial \tau}+t L \frac{\partial w}{\partial \tau}+K=(1-\mu t) K \\
\mathcal{T}_{\tau} & :=\left(\tau \frac{K}{L} \varepsilon_{L}^{K}+t f_{L}\right) \frac{\partial L}{\partial \tau}+\tau \frac{K}{r} \varepsilon_{r}^{K}=\frac{\tau f_{L L}-t f_{L} f_{L K}}{A} .
\end{aligned}
$$

\footnotetext{
${ }^{12} \mathrm{An}$ alternative representation may be obtained by 'solving' eqs (3) and (4) for the tax rates $t$ and $\tau$. As we refer to this alternative representation from time to time, these formulae are provided in Appendix A.
} 
Carefully observe that formula (4) reduces to the well known tax rule given by Zodrow and Mieszkowski (1986), eq. (8) therein, if either labour is left untaxed $(t=0)$ or the equilibrium of the labour market is unaffected by capital taxation ( $w$ and $L$ fixed):

$$
V^{\prime}(G)=\frac{1}{1+\frac{\tau}{r} \varepsilon_{r}^{K}}
$$

This sheds some more additional light onto the result of Zodrow and Mieszkowski, as it may properly be interpreted in a somewhat broader framework. In general, however, neither is the labour tax equal to zero, nor is the outcome on the labour market unaffected by capital taxation, as we have seen. So we turn back to the general case and elaborate this further.

First note that both the numerator and the denominator of the right hand side of eq. (3) and (4) must be positive, for in any equilibrium the marginal rate of substitution between the private and the public good must be positive. Otherwise, the government would face the decreasing branch of the Laffer curve implying that a free lunch, higher private consumption together with a higher provision level of public services, were available. Thus, formally we have $\mathcal{Z}_{t}>0$ and $\mathcal{Z}_{t}+\mathcal{T}_{t}>0$ as well as $\mathcal{Z}_{\tau}>0$ and $\mathcal{Z}_{\tau}+\mathcal{T}_{\tau}>0$. Secondly, since the left-hand sides of eqs (3) and (4) coincide, the right hand sides must do so as well. This implies that the question whether public services are under- or overprovided in equilibrium may be answered by inspection of the sign of either $\mathcal{T}_{t}$ or $\mathcal{T}_{\tau}$. More precisely, in any equilibrium we have

$$
V^{\prime}(G) \gtreqless 1 \quad \Leftrightarrow \quad \mathcal{T}_{t} \lesseqgtr 0 \quad \Leftrightarrow \quad \mathcal{T}_{\tau} \lesseqgtr 0 .
$$

The latter equivalence that $T_{t}$ and $T_{\tau}$ must have the same sign, can be expressed as $T_{t} T_{\tau}>0$ or equivalently as

$$
\left(t f_{L} f_{K K}-\tau f_{L K}\right)\left(\tau f_{L L}-t f_{L} f_{L K}\right)>0
$$

Case 1: $f_{L K}>0$. When capital and labour are complements, public services are overprovided if, and only if, $\tau<t \frac{f_{L} f_{K K}}{f_{L K}}$ and $t<\tau \frac{f_{L L}}{f_{L} f_{L K}}$. Since both fraction terms are negative, we have $t>0 \Rightarrow \tau<0$ and $\tau>0 \Rightarrow t<0$. On the other hand, since at least one tax rate must be strictly positive, we also have $\tau<0 \Rightarrow t>0$ and $t<0 \Rightarrow \tau>0$. That is, overprovision requires that one tax rate is negative while the other is positive. Conversely, when both tax rates are non-negative, public services are underprovided. In other words, if the government is required to tax both capital and labour at positive rates, public funds are relatively scarce in the sense that public services are underprovided; and only if one factor is subsidized 
(while the other is taxed at a positive rate), can public services be overprovided. ${ }^{13}$ Intuitively, when capital and labour are sufficiently strong complements, a subsidy on one factor may help to increase the demand for both factors such that the revenue from the taxed factor suffices to finance the efficient provision level of public services. Or to put it the other way, when public services are overprovided one tax rate is highly efficient in collecting public funds such that the government can afford to refund households by subsidizing the other factor.

Case 2: $f_{L K}<0$. First observe that when capital and labour are substitutes, condition (5) implies that $\operatorname{sgn} t \neq \operatorname{sgn} \tau$ is impossible, and thus requires $\operatorname{sgn} t=$ $\operatorname{sgn} \tau$. Since at least one tax rate must be positive, it follows that both must be so. Next observe that overprovision of public services, that is conditions $\mathcal{T}_{t}>0$ and $\mathcal{T}_{\tau}>0$ are equivalent to

$$
\tau \frac{f_{L L}}{f_{L} f_{L K}}<t<\tau \frac{f_{L K}}{f_{L} f_{K K}}
$$

implying $\left(f_{L L} f_{K K}-f_{L K}^{2}\right) \tau=A \tau<0 \Leftrightarrow \tau<0 \Rightarrow t>0$ - a contradiction, as we already know that $\operatorname{sgn} t=\operatorname{sgn} \tau$. Thus, if $f_{L K}$ is negative, public services must be underprovided in equilibrium. We summarize these results in

Proposition 1. In any tax-competition equilibrium, overprovision of public services can only occur if either the capital or the labour tax rate is negative, which in turn can only materialize when capital and labour are complements, i.e., $f_{L K}>0$. If, however, both factors are substitutes, i.e., $f_{L K}<0$, both tax rates are positive, and the resulting tax yield does not suffice to provide the efficient level of public services.

Note that Proposition 1 implies that in the standard case where public goods are underprovided, the tax rate on capital (along with the tax rate on labour) is positive. This result is fully in line with the empirical observation that most governments impose positive, and frequently even high, tax rates on capital.

We proceed to argue that even if capital and labour are complements, overprovision should be considered as a rather pathological outcome. In order to see this, it is illustrative to inspect two special cases of our model: (i) a CES production function and (ii) a competitive labour market.

CES Production Function. Suppose that the production technology may be described by a CES production function,

$$
f(K, L)=\left(\delta K^{\nu}+(1-\delta) L^{\nu}\right)^{\xi / \nu},
$$

\footnotetext{
${ }^{13}$ In Appendix B we provide an example demonstrating that the reverse does not hold. That is, capital may be subsidized, even though public services are underprovided.
} 
with $\delta \in(0,1), \xi \in(0,1), \nu \in(0,1)$ and $\xi>\nu$. Note that the latter condition is equivalent with $f_{L K}>0$, implying that overprovision of public goods requires one tax rate to be negative and one to be positive. ${ }^{14}$

Using eqs (3) and (4) and 'solving' the result for $t$ and $\tau$ provides us with two tax formulae, analogous to those above. Since, in the general case, the result is pretty unwieldy and does not provide any immediate insights, we relegate these formulae to Appendix A. Yet, applying the specification of a CES production function, evaluating the formula for $t$ at $\mu=0$ yields

$$
\left.t\right|_{\mu=0}=(1-\xi) \frac{V^{\prime}-1}{V^{\prime}},
$$

implying $t \gtreqless 0 \Leftrightarrow V^{\prime} \gtreqless 1$. Moreover, it is straight forward, but tedious, to show that

$$
\frac{\partial t}{\partial \mu} \gtreqless 0 \quad \Leftrightarrow \quad V^{\prime} \gtreqless 1,
$$

i.e., $\operatorname{sgn} \frac{\partial t}{\partial \mu}=\operatorname{sgn}\left(V^{\prime}-1\right)$. Now, suppose public services were overprovided in equilibrium, $V^{\prime}<1$. Then $t$ would be a monotonically decreasing function of $\mu$, and since $\left.t\right|_{\mu=0}<0$, we had $t<0, \forall \mu>0$.

Next, we investigate the term $\mathcal{T}_{\tau}$; and to this end, we differentiate it with respect to $t$ yielding

$$
\frac{\partial \mathcal{T}_{\tau}}{\partial t}=-\frac{K L^{\nu}(1-\delta)(\xi-\nu)}{\left(\delta K^{\nu}+(1-\delta) L^{\nu}\right)(1-\nu)(1-\xi)}<0 .
$$

Moreover, due to the public budget constraint, $t$ is bounded from below by $t \geq$ $-\frac{\tau K}{w L}=: \underline{t}$. Evaluating $\mathcal{T}_{\tau}$ at $\underline{t}$ we find

$$
\left.\mathcal{T}_{\tau}\right|_{t=\underline{t}} \lesseqgtr 0 \quad \Leftrightarrow \quad \tau \gtreqless 0 .
$$

Exploiting the fact that $t$ being negative implies $\tau$ being strictly positive, we conclude $\left.\mathcal{T}_{\tau}\right|_{t=\underline{t}}<0$; but together with $\frac{\partial \mathcal{T}_{\tau}}{\partial t}<0$ this implies $\mathcal{T}_{\tau}<0, \forall t>\underline{t}$, which, however, is at variance with our assumption that public goods are overprovided. We thus conclude

Proposition 2. Let production be characterized by a CES production function. In any tax-competition equilibrium, both the capital and the labour tax rate are positive, and the resulting tax proceeds fall short of the amount necessary to finance the efficient level of public services, i.e., public goods are underprovided.

\footnotetext{
${ }^{14}$ Note that we may safely disregard the case $\xi<\nu$, since for $f_{L K}<0$ we have already shown that public services are underprovided in equilibrium, irrespective of the specification of the production function.

Also note that for consistency with our assumption that $\hat{f}$ is linearly homogeneous, c. f.. fn 7 , the degree of homogeneity of $f$, which equals $\xi$, must fall short of unity.
} 
Proposition 2 demonstrates that for a broad class of frequently used production functions neither does overprovision of public goods emerge, nor is one factor, presumably capital, subsidized in equilibrium.

Competitive labour market. Formally, a competitive labour market is captured by setting $\mu=0$, which implies $w=f_{L}$. Then, following the same procedure as above we obtain

$$
\begin{aligned}
t & =-\frac{V^{\prime}-1}{V^{\prime}} \frac{L f_{L L}+K f_{L K}}{f_{L}} \\
\tau & =-\frac{V^{\prime}-1}{V^{\prime}}\left(L f_{L K}+K f_{K K}\right) .
\end{aligned}
$$

Assume that the production function $f$ is homogeneous of degree $\xi<1$, which may be formalized as $K f_{K}+L f_{L}=\xi f$. By differentiation with respect to $L$ this implies $K f_{L K}+L f_{L L}=(\xi-1) f_{L}<0$; and by differentiation with respect to $K$, we obtain $L f_{L K}+K f_{K K}=(\xi-1) f_{K}<0$. Using this, tax formulae (7) and (8) imply $\operatorname{sgn} t=\operatorname{sgn} \tau=\operatorname{sgn}\left(V^{\prime}-1\right)$. Since at least one tax rate must be positive, we conclude that both $t$ and $\tau$ must be positive and hence $V^{\prime}>1$. We thus arrive at

Proposition 3. Let the production function $f$ be homogeneous of degree $\xi<1$, and assume that the labour market is competitive. In any tax-competition equilibrium, both the capital and the labour tax rate are positive, and public services are underprovided.

Proposition 3 complements our previous findings by showing that overprovision of public goods and subsidization of capital can not only be regarded as a pathologic outcome for efficient bargains, but also for a competitive labour market.

Finally, formulae (7) and (8) allow for a comparison of the tax shares to be borne by capital and labour. Using the homogeneity of $f$, eqs (7) and (8) imply

$$
t=\frac{V^{\prime}-1}{V^{\prime}}(1-\xi)=\frac{\tau}{r}
$$

That is, the equilibrium tax rates are proportional to each other, $\tau=r t$. Using this result, it immediately follows that

$$
\frac{t w L}{G} \gtreqless \frac{\tau K}{G} \Longleftrightarrow w L \gtreqless r K .
$$

Hence, each factor finances the provision of public goods relative to its (pre-tax) income share: The more a factor earns, the more it contributes to public funds. 


\section{Conclusion}

In the present paper we have analyzed tax competition when governments compete over capital and labour taxes in the classical Zodrow-Mieszkowski model extended by involuntary unemployment. Using an efficient bargaining approach à la Nash, it turns out that if capital and labour are substitutes in production or if the production function is of CES-type, tax competition leads to underprovision of public goods and both tax rates are positive. For that reason the original Zodrow and Mieszkowski results are quite robust with respect to the presence of involuntary unemployment (at least for efficient Nash bargains) and with respect to the introduction of labour taxes. This implies that the cases of (i) overprovision of public services and (ii) subsidization of capital seem to be rather pathological outcomes. As a consequence, the results of Fuest and Huber (1999) and Ogawa et al. (2006), are very sensitive to their models' specification. The negative capital tax rate in Fuest and Huber (1999) hinges upon the assumption that profits are fully taxed away, while the overprovision result of Ogawa et al. (2006) depends on the fixed wage and the absence of labour taxes.

Within a more general framework where capital and labour demand, along with the wage rate, are fully endogenous and thus interdependent, the effects induced by either capital or labour taxation are roughly comparable. In this respect the technological feature whether capital and labour are substitutes or complements, essentially plays a subordinate role. Only for non-standard production functions featuring a severe complementarity between the two factors may a nonstandard result, that is overprovision and/or subsidization of one factor, emerge. If, however, we disregard these polar specifications, and allow for both factors to be taxed along with a flexible wage rate and endogenous determination of employment, we find that the results derived by Zodrow and Mieszkowski (1986) are more robust with respect to modifications of the model than one might expect. Finally, with distortions on the labour market, there is little scope for the claim that, from the viewpoint of optimal taxation, labour taxes are generally superior to capital taxes.

In our model we have abstracted from many other real world features, though. For example, we did not allow for large, possibly asymmetric countries; nor did we consider households with heterogeneous preferences. Heterogeneity of households is, however, a necessary prerequisite for studying distributional effects and thus for nonlinear income taxation. Finally, one may consider the provision of public goods that benefit firms rather than households, such as infrastructure. These issues may represent fruitful routes for future research, but are beyond the scope of the present paper. 


\section{Appendix A.}

Instead of solving each of the two equations $\frac{\partial W}{\partial t}=0$ and $\frac{\partial W}{\partial \tau}=0$ for $V^{\prime}(G)$ and then comparing the right-hand sides, we may alternatively 'solve' the system $\frac{\partial W}{\partial t}=0=\frac{\partial W}{\partial \tau}$ for the two tax rates. This procedure yields

$$
\begin{aligned}
t & =\frac{\left(V^{\prime}-1\right)\left(f_{L K} f_{L} K+f_{L L} L w\right)}{\mathcal{N}}, \\
\tau & =\frac{\left(V^{\prime}-1\right)}{V^{\prime}} \frac{V^{\prime} f_{L}\left(f_{K K} f_{L} K+f_{L K} L w\right)-\left(V^{\prime}-1\right)(1-\mu)\left(w-f_{L}\right) A K L}{\mathcal{N}},
\end{aligned}
$$

with $\mathcal{N}:=\left(V^{\prime}-1\right)\left(\mu f_{L}\left(f_{L K} K+f_{L L} L\right)+f_{L L} L\left(w-f_{L}\right)\right)-f_{L}^{2} V^{\prime}$.

We have used these formulae to derive Proposition 3.

\section{Appendix B.}

Consider the following production function

$$
f(L, K)=\left(1-\exp \left(-L^{-1 / 4} K^{-1 / 8}\right)\right)^{-1} .
$$

Let residents' aggregate utility of the public good be given by $V(G)=\sqrt{G}$; and private reservation utility, by $\bar{u}=1$. Finally, let $\bar{K}=1$. Then a symmetric tax equilibrium (or any equilibrium with an equilibrium net return $\rho=0.0514208$ ) is given by

$$
t=0.330154 \text { and } \tau=-0.00710809
$$

implying

$$
L=0.0593654, \quad K=1, \quad w=10.0751, \quad G=0.190361
$$

and $f_{L}=1.49288, f_{K}=0.0443127, f_{L L}=-14.8281, f_{K K}=-0.0352209, f_{L K}=$ 0.306301 and $A=0.42844$. Evaluating $V^{\prime}$ at the equilibrium provision level yields $V^{\prime}(0.190361)=1.14599>1$. We thus conclude that public services are underprovided, although capital is subsidized.

\section{References}

T. Aronsson and S. Wehke. Public goods, unemployment and policy coordination. Regional Science and Urban Economics, 38:285-298, 2008.

Th. Bayındır-Upmann and M. G. Raith. Should high-tax countries pursue revenueneutral ecological tax reforms? European Economic Review, 47:41-60, 2003.

Th. Bayındır-Upmann and M. G. Raith. Unemployment and pollution: Is one policy suited for two problems? The Economic Record, 81:378-393, 2005.

S. Bucovetsky and J. D. Wilson. Tax competition with two tax instruments. Regional Science and Urban Economics, 21:333-350, 1991. 
J. Creedy and I. M. McDonald. Models of trade union behaviour: A synthesis. The Economic Record, 67:346-359, 1991.

Eurostat. Taxation trends in the eu: Eu27 tax ratio at 39.9\% of gdp in 2006. Eurostat newsrelease, 2008.

C. Fuest and B. Huber. Tax coordination and unemployment. International Tax and Public Finance, 6(1):7 - 26, 1999.

J. J. Gabszewicz and T. van Ypersele. Social protection and political competition. Journal of Public Economics, 61:193-208, 1996.

A. Gerber and Th. Upmann. Bargaining solutions at work: Qualitative differences in policy implications. Mathematical Social Sciences, 52:162-175, 2006.

E. Koskela and R. Schöb. Optimal factor income taxation in the presence of unemployment. Journal of Public Economic Theory, 4(3):387 - 404, 2002.

Arjan M. Lejour and Harrie A. A. Verbon. Capital mobility, wage bargaining, and social insurance policies in an economic union. International Tax and Public Finance, 3(4):495-513, 1996.

H. Ogawa, Y. Sato, and T. Tamai. A note on unemployment and capital tax competition. Journal of Urban Economics, 60:350 - 356, 2006.

W. Richter and K. Schneider. Taxing mobile capital with labour market imperfections. International Tax and Public Finance, 8:245-262, 2001.

Th. Upmann. A positive analysis of labor-market institutions and tax reforms. International Tax and Public Finance, 16:621-646, 2009.

G. R. Zodrow and P. Mieszkowski. Pigou, Tiebout, property taxation, and the underprovision of local public goods. Journal of Urban Economics, 19:356 - 70, 1986. 


\section{CESifo Working Paper Series}

for full list see www.cesifo-group.org/wp

(address: Poschingerstr. 5, 81679 Munich, Germany, office@cesifo.de)

2985 Francesca Barion, Raffaele Miniaci, Paolo M. Panteghini and Maria Laura Parisi, Profit Shifting by Debt Financing in Europe, March 2010

2986 Alexander Haupt and Magdalena Stadejek, The Choice of Environmental Policy Instruments: Energy Efficiency and Redistribution, March 2010

2987 John Komlos and Marek Brabec, The Trend of BMI Values among US Adults, March 2010

2988 Emanuele Massetti and Lea Nicita, The Optimal Climate Policy Portfolio when Knowledge Spills across Sectors, March 2010

2989 Helmut Rainer and Thomas Siedler, Family Location and Caregiving Patterns from an International Perspective, March 2010

2990 Toru Kikuchi and Ngo Van Long, A Simple Model of Service Offshoring with Time Zone Differences, March 2010

2991 Assaf Razin, Efraim Sadka and Benjarong Suwankiri, Migration and the Welfare State: Dynamic Political-Economy Theory, March 2010

2992 Bård Harstad, Buy Coal! Deposit Markets Prevent Carbon Leakage, March 2010

2993 Axel Dreher, Stephan Klasen, James Raymond Vreeland and Eric Werker, The Costs of Favoritism: Is Politically-driven Aid less Effective?, March 2010

2994 Sven Neelsen and Thomas Stratmann, Effects of Prenatal and Early Life Malnutrition: Evidence from the Greek Famine, March 2010

2995 Claude Hillinger and Bernd Süssmuth, The Quantity Theory of Money: An Assessment of its Real Linchpin Prediction, March 2010

2996 Matthew M. Chingos and Martin R. West, Do More Effective Teachers Earn More Outside of the Classroom?, March 2010

2997 Laurence Jacquet and Dirk Van de gaer, A Comparison of Optimal Tax Policies when Compensation or Responsibility Matter, March 2010

2998 Valentina Bosetti, Carlo Carraro, Romain Duval and Massimo Tavoni, What Should we Expect from Innovation? A Model-Based Assessment of the Environmental and Mitigation Cost Implications of Climate-Related R\&D, March 2010

2999 Scott Alan Carson, Nineteenth Century Stature and Family Size: Binding Constraint or Productive Labor Force?, March 2010 
3000 Jukka Pirttilä and Ilpo Suoniemi, Public Provision, Commodity Demand and Hours of Work: An Empirical Analysis, March 2010

3001 Bertrand Candelon and Franz C. Palm, Banking and Debt Crises in Europe: The Dangerous Liaisons?, March 2010

3002 Joan Costa-i-Font and Marin Gemmill-Toyama, Does Cost Sharing really Reduce Inappropriate Prescriptions?, March 2010

3003 Scott Barrett, Climate Treaties and Backstop Technologies, March 2010

3004 Hans Jarle Kind, Tore Nilssen and Lars Sørgard, Price Coordination in Two-Sided Markets: Competition in the TV Industry, March 2010

3005 Jay Pil Choi and Heiko Gerlach, Global Cartels, Leniency Programs and International Antitrust Cooperation, March 2010

3006 Aneta Hryckiewicz and Oskar Kowalewski, Why do Foreign Banks Withdraw from other Countries? A Panel Data Analysis, March 2010

3007 Eric A. Hanushek and Ludger Woessmann, Sample Selectivity and the Validity of International Student Achievement Tests in Economic Research, March 2010

3008 Dennis Novy, International Trade and Monopolistic Competition without CES: Estimating Translog Gravity, April 2010

3009 Yin-Wong Cheung, Guonan Ma and Robert N. McCauley, Renminbising China's Foreign Assets, April 2010

3010 Michel Beine and Sara Salomone, Migration and Networks: Does Education Matter more than Gender?, April 2010

3011 Friedrich Schneider, Tilman Brück and Daniel Meierrieks, The Economics of Terrorism and Counter-Terrorism: A Survey (Part I), April 2010

3012 Friedrich Schneider, Tilman Brück and Daniel Meierrieks, The Economics of Terrorism and Counter-Terrorism: A Survey (Part II), April 2010

3013 Frederick van der Ploeg and Steven Poelhekke, The Pungent Smell of "Red Herrings": Subsoil Assets, Rents, Volatility and the Resource Curse, April 2010

3014 Vjollca Sadiraj, Jan Tuinstra and Frans van Winden, Identification of Voters with Interest Groups Improves the Electoral Chances of the Challenger, April 2010

3015 Guglielmo Maria Caporale, Davide Ciferri and Alessandro Girardi, Time-Varying Spot and Futures Oil Price Dynamics, April 2010

3016 Scott Alan Carson, Racial Differences in Body-Mass Indices for Men Imprisoned in $19^{\text {th }}$ Century US Prisons: A Multinomial Approach, April 2010 
3017 Alessandro Fedele, Paolo M. Panteghini and Sergio Vergalli, Optimal Investment and Financial Strategies under Tax Rate Uncertainty, April 2010

3018 Laurence Jacquet, Take it or Leave it: Take-up, Optimal Transfer Programs, and Monitoring, April 2010

3019 Wilhelm Kohler and Jens Wrona, Offshoring Tasks, yet Creating Jobs?, April 2010

3020 Paul De Grauwe, Top-Down versus Bottom-Up Macroeconomics, April 2010

3021 Karl Ove Aarbu, Demand Patterns for Treatment Insurance in Norway, April 2010

3022 Toke S. Aidt and Jayasri Dutta, Fiscal Federalism and Electoral Accountability, April 2010

3023 Bahram Pesaran and M. Hashem Pesaran, Conditional Volatility and Correlations of Weekly Returns and the VaR Analysis of 2008 Stock Market Crash, April 2010

3024 Stefan Buehler and Dennis L. Gärtner, Making Sense of Non-Binding Retail-Price Recommendations, April 2010

3025 Leonid V. Azarnert, Immigration, Fertility, and Human Capital: A Model of Economic Decline of the West, April 2010

3026 Christian Bayer and Klaus Wälde, Matching and Saving in Continuous Time: Theory and 3026-A Matching and Saving in Continuous Time: Proofs, April 2010

3027 Coen N. Teulings and Nick Zubanov, Is Economic Recovery a Myth? Robust Estimation of Impulse Responses, April 2010

3028 Clara Graziano and Annalisa Luporini, Optimal Delegation when the Large Shareholder has Multiple Tasks, April 2010

3029 Erik Snowberg and Justin Wolfers, Explaining the Favorite-Longshot Bias: Is it RiskLove or Misperceptions?, April 2010

3030 Doina Radulescu, The Effects of a Bonus Tax on Manager Compensation and Welfare, April 2010

3031 Helmut Lütkepohl, Forecasting Nonlinear Aggregates and Aggregates with Timevarying Weights, April 2010

3032 Silvia Rocha-Akis and Ronnie Schöb, Welfare Policy in the Presence of Unionised Labour and Internationally Mobile Firms, April 2010

3033 Steven Brakman, Robert Inklaar and Charles van Marrewijk, Structural Change in OECD Comparative Advantage, April 2010

3034 Dirk Schindler and Guttorm Schjelderup, Multinationals, Minority Ownership and TaxEfficient Financing Structures, April 2010 
3035 Christian Lessmann and Gunther Markwardt, Decentralization and Foreign Aid Effectiveness: Do Aid Modality and Federal Design Matter in Poverty Alleviation?, April 2010

3036 Eva Deuchert and Conny Wunsch, Evaluating Nationwide Health Interventions when Standard Before-After Doesn't Work: Malawi's ITN Distribution Program, April 2010

3037 Eric A. Hanushek and Ludger Woessmann, The Economics of International Differences in Educational Achievement, April 2010

3038 Frederick van der Ploeg, Aggressive Oil Extraction and Precautionary Saving: Coping with Volatility, April 2010

3039 Ainura Uzagalieva, Evžen Kočenda and Antonio Menezes, Technological Imitation and Innovation in New European Union Markets, April 2010

3040 Nicolas Sauter, Jan Walliser and Joachim Winter, Tax Incentives, Bequest Motives, and the Demand for Life Insurance: Evidence from two Natural Experiments in Germany, April 2010

3041 Matthias Wrede, Multinational Capital Structure and Tax Competition, April 2010

3042 Burkhard Heer and Alfred Maussner, A Note on the Computation of the Equity Premium and the Market Value of Firm Equity, April 2010

3043 Kristiina Huttunen, Jukka Pirttilä and Roope Uusitalo, The Employment Effects of Low-Wage Subsidies, May 2010

3044 Matthias Kalkuhl and Ottmar Edenhofer, Prices vs. Quantities and the Intertemporal Dynamics of the Climate Rent, May 2010

3045 Bruno S. Frey and Lasse Steiner, Pay as you Go: A New Proposal for Museum Pricing, May 2010

3046 Henning Bohn and Charles Stuart, Population under a Cap on Greenhouse Gas Emissions, May 2010

3047 Balázs Égert and Rafal Kierzenkowski, Exports and Property Prices in France: Are they Connected?, May 2010

3048 Thomas Eichner and Thorsten Upmann, Tax-Competition with Involuntary Unemployment, May 2010 